Justicia Juris, ISSN 1692-8571, Vol. 8. No 1. Enero - Junio 2012 Pág. 9-21

\title{
La naturaleza jurídica de las cajas de compensación en Colombia: una visión frente a su control
}

\section{The legal nature of compensation funds in Colombia: a view of its control}

\author{
VICTORIA RODRÍGUEZ ARÉVALO
}

\begin{abstract}
Abogada, magister en Derecho, especialista en Gerencia Social y en Derecho Comercial; docente de la Universidad Autónoma del Caribe. Miembro del Grupo de Investigación de Género, Niñez y Criminalidad. vickro1130@hotmail.com
\end{abstract}

Recibido: Marzo 24 de 2012

Aceptado: Mayo 26 de 2012

RESUMEN

En este artículo de reflexión se analiza el tema relacionado con las funciones asignadas a las Cajas de Compensación Familiar, tomando como punto de partida la Ley 21 de 1982, norma que las concibió como redistribuidoras a favor de sus afiliados de las contribuciones pagadas por los empleadores, con atribuciones en el campo de la seguridad social, frente a la posterior ampliación de sus actividades a través de las modificaciones del régimen legal aplicable a la naturaleza jurídica de esta entidades, y su desarrollo jurisprudencial que no facilita percibir una clara e inequívoca integralidad en la regulación que permita a su vez a las Cajas de compensación la articulación de sus recursos, actividades y modos de operación, así como su ubicación en el esquema de la seguridad social y en los otros sectores económicos y sociales relacionados. Lo anterior ha traído como consecuencia, la dispersión en el régimen de inspección, vigilancia y control y la falta de claridad en cuanto a la interpretación y aplicación de las normas, situaciones que afectan el dinamismo que debe acompañar a las Cajas de Compensación, acordes con la responsabilidad social y económica que le son propias.

Palabras clave: Funciones, Cajas de Compensación familiar, redistribuidoras, contribuciones, naturaleza jurídica, desarrollo jurisprudencial, integralidad en la regulación, régimen de inspección, vigilancia y control

\begin{abstract}
In this reflective paper tries to analyse the functions assigned to the family compensation funds, taking as its starting point the Act 21 of 1982, which define them as the rights that their members have for the contributions paid by employers. These family compensation funds are linked to the Social security system and its amendments to the legal regime in terms of expansion of its activities. The jurisprudential development does not provide a clear understanding on how these funds can articulate their resources, activities and modes of operation as well as its location in the social security scheme and the other economic and social issues. As a result, the regime of inspection, supervision and control is dispersed, and there is lack of clarity regarding the interpretation and application of standards that affect the dynamic situations that must accompany these Compensation Funds, in line with economic and social responsibility.

Key words: Roles, Family Compensation funds, redistributive, taxes, legal nature, jurisprudential development, integrity in the regulation, inspection regime, monitoring and control
\end{abstract}




\section{Introducción}

El planteamiento de este artículo se fundamenta en la necesidad de establecer, a través de un enfoque cualitativo, y a través de una investigación jurídica, cual es el régimen de vigilancia y control al que se encuentran sometidas las cajas de compensación familiar en la actualidad, ante la diversidad de funciones que actualmente cumplen y que se relacionan con diferentes entes de vigilancia y control del Estado. Para ello se parte de un análisis descriptivo de las funciones asignadas a estas corporaciones, a partir de la ley 21 de 1982, observando su desarrollo jurisprudencial en Colombia hasta la fecha, en relación a la naturaleza jurídica de las cajas de compensación y precisando con base en lo anterior, como está operando el control y vigilancia en las Cajas en el ejercicio de sus diversas actividades conforme a la ley.

Las cajas de compensación familiar fueron concebidas como corporaciones sin animo de lucro, en el cumplimiento de las funciones establecidas en la ley 21 de 1982. Impulsadas por las realidades socio-económicas imperantes, que se refleja en los cambios en la normatividad vigente, se le han asignado una variedad de funciones de las que se derivan múltiples responsabilidades, lo que exige necesariamente un análisis reflexivo del rol que cumplen estas entidades en la actualidad, su operatividad y su control y vigilancia.

Estas entidades, han sido reconocidas, desde sus orígenes, como instituciones líderes en la formulación y ejecución de programas sociales, lo que resalta la importancia de este tema, liderazgo que el Gobierno colombiano ha reconocido, en diferentes circunstancias, asignándoles funciones sociales que le corresponderían al Estado constitucionalmente, ante la necesidad de generar soluciones a los graves problemas sociales y económicos que enfrenta el país. Estas nuevas situaciones han requerido por parte del sistema de cajas la necesidad de implementar estrategias para generar más ingresos, contar con una mayor y mejor infraestructura, mayor exigencia de recurso humano especializado, mejor planeación administrativa, aplicación de tecnología, y por ende exige del Estado la aplicación de adecuados mecanismos de control y vigilancia. A todo lo anterior se agrega, la creciente tendencia de ser autosuficientes en la generación de ingresos.

Las cajas de compensación se constituyen en una clara expresión de un actor de derecho privado, financiado por aportes del sector empresarial, pero con una importante actuación en lo público por el carácter social de los beneficios que generan, por lo que se destacan como operadores inmersos dentro de la estructura del complejo económico y social del país.

Las conclusiones de este artículo se basan en el resultado del análisis de la regulación legal y jurisprudencial de las
Cajas de Compensación, aunado al de la doctrina, con referencia a la realidad política, económica y social de nuestro país, aspectos que han incidido directamente en su naturaleza jurídica.

\section{Breve reseña histórica de su regulación}

Para internarse en el estudio de la naturaleza jurídica con que fueron concebidas las cajas de compensación, es necesario observar la evolución regulatoria del subsidio familiar, partiendo de la ley 21 de 1982, dicha norma definió las cajas de compensación familiar, en concepto aún vigente, como una entidad de origen legal y de naturaleza especialísima ${ }^{1}$ tal como lo estableció la Corte Suprema de Justicia al manifestar

...no es una actividad privada la que cumplen, ni son los bienes que le pertenezcan en la forma de propiedad privada adquirida con justo titulo, lo que hace a las cajas entes de derecho privado; todo lo contrario, son las actividades de interés general y los bienes que están destinados a lograr el bienestar de los trabajadores y sus familias lo que las configura como entes de origen legal, y de naturaleza especial que se organizan bajo las reglas de derecho privado.

Y por otro lado en atención a su función como administradora del subsidio familiar de los trabajadores ${ }^{2}$.Es en esta ley, donde se establecieron las condiciones de igualdad en el acceso al subsidio para todos los trabajadores.

Es en los años 80, cuando el legislador crea la Superintendencia de Subsidio Familiar ${ }^{3}$, a través de la ley 25 de 1981, como un organismo de derecho público encargado de ejercer las funciones de inspección y vigilancia de las entidades autorizadas para recaudar los aportes y pagar las asignaciones del subsidio familiar. El subsidio se había establecido como reconocimiento en dinero para los trabajadores con remuneración salarial fija o variable que no sobrepasara los cuatro salarios mínimos legales mensuales vigentes, con

\footnotetext{
Ver Corte Suprema de Justicia. Sala Plena. Sentencia No. 32 de 1987. M. P : Fabio Morón Díaz.

2 personas jurídicas de derecho privado, sin ánimo de lucro, organizadas como corporaciones...,cumplen funciones de seguridad social y se hallan sometidas al control y vigilancia del Estado... (Articulo 39, Ley 21 de 1982). Su función es administrar el subsidio familiar, prestación social pagadera en dinero, especie y servicios a los trabajadores de medianos y menores ingresos, en proporción al número de personas a su cargo... (Artículo 1, Ley 21 de 1982).

3 los artículos 3o. de la Ley 25 de 1981 y 54 numeral 2o. de la Ley 21 de 1982, le confieren facultad a la Superintendencia del Subsidio Familiar para ejercer la inspección y vigilancia de las entidades encargadas de recaudar los aportes y pagar el subsidio familiar, con el propósito de que su constitución, funcionamiento y la realización de sus obras y programas sociales se ajusten a las leyes, decretos y estatutos interno.
} 
algunos límites especiales en topes de cotización y clases de servicios. Con la expedición de la ley 71 de $1989^{4}$, se extendió esta prestación a los pensionados, con excepción del subsidio en dinero.

Los recursos necesarios para el reconocimiento de estos subsidios, llamados parafiscales ${ }^{5}$, que hacen relación, al decir de la Corte Constitucional en su sentencia C-575 de Octubre 19 de 1992 a unos "recursos extraídos en forma obligatoria de un sector económico para ser reinvertidos en el propio sector, con exclusión del resto de la sociedad", provienen de las cotizaciones obligatorias impuestas a cargo de los patronos ${ }^{6}$, hoy llamados empleadores.

La norma definió una estructura organizacional y jurídica uniforme, para las cajas de compensación familiar integradas por la Asamblea General, el Consejo Directivo y el Director Administrativo.

El decreto 784 de 1989 reguló las modalidades de subsidio en especie, consecuentemente la mayoría de las cajas organizó su portafolio de servicios en, al menos, seis programas: mercadeo social, salud, educación, vivienda, fomento y recreación, siguiendo el orden de prioridades señaladas en el artículo 62 de la ley 21 del $82^{8}$.

4 Ley 71 de 1989, artículo 6o. Las Cajas de Compensación Familiar deberán prestar a los pensionados, mediante previa solicitud, los servicios a que tienen derecho los trabajadores activos.

Para estos efectos los pensionados cotizarán de acuerdo con los reglamentos que expida el gobierno nacional, sin que en ningún caso la cuantía de la cotización sea superior al dos por ciento $(2 \%)$ de la correspondiente mesada.

5 Corte Constitucional. Sentencia No. C-449, del 9 de julio de 1992.M. P. Alejandro Martínez Caballero.

6 “ (...) las cotizaciones que los patronos realizan a las Cajas son aportes obligatorios que se reinvierten en el sector. Su fundamento constitucional se encuentra hoy en el artículo 150 numeral 12 y en el 338 ídem. Sentencia No. C-449 de 1992.Corte Constitucional.

7 Decreto 341 , febrero 25 de 1988 artículos 8 y 27 y Superintendencia De Subsidio Familiar, Circular 007 de 1988.

8 Las obras y programas sociales que emprendan las Cajas de Compensación con el fin de atender el pago del subsidio en servicios o especie, se realizarán exclusivamente en los campos y en el orden de prioridades que a continuación se señala:

$1^{\circ}$ Salud

$2^{\circ}$ Programas de nutrición y mercadeo de productos alimenticios y otros que compongan la canasta familiar para ingresos bajos (obreros), definida por el Departamento Administrativo nacional de Estadística (DANE)

$3^{\circ}$ Educación integral y continuidad; capacitación y servicios de biblioteca.

$4^{\circ}$ Vivienda

$5^{\circ}$ Crédito de fomento para industrias familiares

$6^{\circ}$ Recreación social

$7^{\circ}$ Mercadeo de productos diferentes a los enunciados en el ordinal $2^{\circ}$; el cual se hará de acuerdo con la reglamentación que expida posteriormente el Gobierno Nacional.

"Parágrafo. El Ministerio de Trabajo y Seguridad Social, previo visto bueno del Consejo Superior del Subsidio Familiar, teniendo en cuenta las condiciones de vida familiar de los trabajadores benefi-
La Corte Constitucional, en sentencia C-575 de octubre 29 de 1992 al declarar exequible los numerales segundo y tercero del artículo 68 de la ley 49 de 1990, en referencia de la evolución normativa, concluye estableciendo cuatro transformaciones significativas en la historia de las cajas de compensación:

...Primero, el subsidio familiar pasó de ser una ayuda voluntaria a una obligación institucional." Con el establecimiento de un nuevo orden regulatorio, a través de la ley 21 del 82 , teniendo en cuenta que sus recursos provienen de contribuciones de carácter parafiscal, que son de observancia obligatoria en su pago para los empleadores que tengan a su cargo trabajadores en relación laboral, y que se orientan hacia el interior del sistema, a cubrir un nivel mínimo de subsidios en dinero, a atender la reserva legal de las Cajas, a contribuir al funcionamiento del órgano administrativo de control estatal y a satisfacer los gastos de administración de las corporaciones (Cortes, 2004.p.19).

- "Segundo, las Cajas de Compensación pasaron de ser simples intermediarios entre los empleadores y los trabajadores a ser un redistribuidor regular de los recursos", bajo un esquema de compensación entre empresas, se le reconocía una suma de dinero a los trabajadores de menos ingresos, conforme a las personas que tuviera a cargo ${ }^{\text {, }}$

-"Tercero, de un simple subsidio en dinero se pasó a un sistema integral de distribución de subsidios en dinero, en especie y en servicios" con programas de acción social en los campos de salud, educación y alimentación, mercadeo, vivienda, en infraestructura como centros vacacionales, supermercados o centros de educación.

$\mathrm{Y}$, "cuarto, de una cobertura limitada a los trabajadores de los empleadores que cotizaban, se pasó a una universalización de los servicios para toda la sociedad"10, Se amplía el ámbito de acción de las Cajas, así como frente a nuevos sectores de la población, en la construcción del tejido del bienestar social del país con finalidades tales como la vivienda de interés social, salud, y educación

Así es como, de la nueva concepción de la actuación del Estado Social de Derecho, que va aparejada con la justicia social y el logro de una prosperidad general, entendida como finalidad del mismo, es la que hace participe a las

ciarios y las circunstancias económicas y sociales que imperen en la respectiva zona territorial podrá modificar el anterior orden de prioridades.

Ver Decreto 341 de febrero 25 de 1988,considerandos 2 y 4.

10 Ver Corte Constitucional, sentencia c-575.octubre 19 de 1992,M. P. Alejandro Martínez Caballero. 
Cajas como herramienta de políticas públicas. ${ }^{11}$ En aplicación del principio de solidaridad y por mandato legal de atención del subsidio a la demanda, se instituyó el subsidio a la vivienda de interés social por parte de las cajas de compensación familiar y se ordenó destinar el 5\% de los recaudos del subsidio familiar que administren, para financiar el régimen de subsidios en Salud, salvo casos de excepción en que la ley fije un porcentaje superior (leyes 49/90 y 100/93), así como la incorporación de las Cajas en el sistema de educación, a partir de la ley 115 de 1994.

Con la expedición de la ley 100 de 1993, que reforma al régimen de seguridad social en salud, las cajas de compensación familiar, además de involucrarlas como contribuyentes del régimen subsidiado y dada su valorada experiencia se les autorizó para continuar prestando los servicios de salud bajo el nuevo esquema creado, tanto en el régimen contributivo como en el subsidiado, posición, respaldada por la Corte Constitucional al establecer que "La contribución parafiscal que establece el precepto demandado no se queda en el reducido ámbito de los trabajadores que cotizan a las cajas de compensación familiar sino que se proyecta hacia los beneficiarios del régimen subsidiado de salud, incluidos trabajadores independientes y no cotizantes en dichas entidades, pero ello no vicia de inconstitucionalidad el precepto. Por el contrario, se realiza por esa vía el principio general de solidaridad"12. , y que ratifica la extensión en la aplicación de los parafiscales, ya no en el sector de trabajadores dependientes, posición inicial de la Corte Constitucional, sino a una población generalizada, cubierta por este régimen subsidiado en salud.

La Ley 633 de 2000, y el decreto ley 789 de 2002, enfatizan la ampliación de la acción de las Cajas a la atención, no sólo a la población de los trabajadores y sus familias, sino a personas no vinculadas a este sistema en programas de salud, protección integral a la niñez, jornada escolar complementaria, tal como lo señala los artículos 63 y 64 de la ley 633 mencionada $^{13}$, y a través del subsidio al

11 Ver Corte Constitucional, en sentencia T-712 del 15 de agosto del 2003, MP. Jaime Córdoba Triviño. A partir de la legislación vigente, se destacan las siguientes características del subsidio familiar:

- El Subsidio familiar es considerado como una especie del genero de la seguridad social, regido por lo tanto, por los principios de eficiencia, universalidad y solidaridad incorporados en el artículo 49 de la Carta Política, constituye, por ende, una valiosa herramienta para la consecución de los objetivos de la política social y laboral del Gobierno.

12 Ver Corte Constitucional, Sentencia C-183 de 1997. M, P. José Gregorio Hernández.

13 Ley 633 del 2000. En Artículo 64. Destinación de los recursos del Fovis. Los recursos adicionales que se generen respecto de los establecidos con anterioridad a la presente ley se destinarán de la siguiente manera:

a) No menos del cincuenta por ciento (50\%) para vivienda de interés social;

b) El porcentaje restante después de destinar el anterior, para la atención integral a la niñez de cero (0) a seis (6) años y la jornada escolar complementaria. Estos recursos podrán ser invertidos direc- desempleo ${ }^{14}$, micro crédito empresarial ${ }^{15} \mathrm{y}$ capacitación para la inserción laboral ${ }^{16}$, acogida por el decreto ley 789 del 2002, con importantes efectos en la sociedad, al promover la cohesión social y la seguridad entre sus miembros, y con el propósito de lograr la exclusión de mayores grupos sociales del circulo vicioso de la pobreza.

Esta ampliación de cobertura, fue objeto de pronunciamiento por parte de la Corte Constitucional en sentencia C-149 de 1999 que determinó en su jurisprudencia la autonomía legislativa en materia de subsidio familiar, al establecer: "en principio, la constitución reserva al legislador la competencia de regular el servicio público de seguridad social, que debe prestarse con sujeción a los principios de eficiencia, universalidad y solidaridad. El Estado por su parte, con la participación de los particulares, está en la obligación de ampliar la cobertura de la seguridad social -que comprenderá la prestación de los servicios que determine la ley".

Con este pronunciamiento, se estableció al sistema del Subsidio Familiar como género de la Seguridad social y por ende con una doble naturaleza, de servicio público y de derecho constitucional garantizado a todos los habitantes.

Por lo tanto, tal como lo establece el capitulo 5to de la ley 789 del $2002^{17}$ se definen nuevos parámetros para la organización y funcionamiento de las Cajas y se abre otra etapa, que permite a dichas entidades participar, asociarse, invertir, constituir otras personas jurídicas, realizar convenios y alianzas estratégicas para el desarrollo de servicios o la distribución de productos, tales como:

“- Potencializar la formación de alianzas estratégicas entre cajas o, con otro tipo de entidades, permitiendo tanto la integración vertical como la horizontal.

- Promover la inversión en el componente de salud en el sistema de la seguridad social, reforzando su vocación hacia el aseguramiento de riesgos de salud.

- Establecer la inversión en el sistema financiero en actividades de micro crédito, abriendo la posibilidad de desarrollo de contratos tales como el Joint venture $\mathrm{u}$ otras formas de contratación con la banca.

- Impulsar el desarrollo denuevas personas jurídicas dentro de su actividad, eliminando las limitaciones existentes.

- Y, permite invertir en fondos de capital de riesgo, previa autorización del gobierno" (Ruiz Gómez, 2003, p.2).

\footnotetext{
tamente en dichos programas abiertos a la comunidad, por las Cajas de compensación sin necesidad de trasladarlos al Fovis.

$14 \quad$ En capítulo 3ro., ley 789 del 2002.

15 En artículo 7, ley 789 del 2002.

$16 \quad$ En artículo 12, ley 789 del 2002.

17 En régimen de Organización y funcionamiento de las Cajas de Compensación Familiar, el artículo16 establece funciones que modifican el artículo 41 de la ley 21 de 1983
} 
La modificación de la ley 789 de 2020, generada por la ley 920 de 2004, autorizó a las Cajas de Compensación Familiar para desarrollar la actividad financiera al establecer en su articulo 1ro. “Adiciónese el artículo 16 de la Ley 789 de 2002 que a su vez modificó el artículo 41 de la Ley 21 de 1982, con el siguiente numeral.14. Autorización general. Las Cajas de Compensación Familiar podrán adelantar la actividad financiera con sus empresas, trabajadores, pensionados, independientes y desempleados afiliados en los términos y condiciones que para el efecto reglamente el Gobierno Nacional...."

A su vez, la ley 828 de 2003, -por medio de la cual se expidieron normas para el control a la evasión en el pago de aportes o contribuciones con destino al sistema de seguridad social, en orden a prevenir y sancionar dichas manifestaciones-, complementa la estructuración de un sistema único de registro para la seguridad en Colombia, con el empleo de tecnologías actuales que permiten el cruce de información y la validación de la suministrada a los diferentes administradores.

\section{Las cajas de compensación y su rol en la actualidad}

A propósito de la naturaleza jurídica de las cajas de compensación, la Corte Constitucional en su sentencia C-559 de 2011 ha sostenido:

...En líneas generales, del anterior panorama de desarrollo histórico puede concluirse que el subsidio familiar en Colombia ha buscado beneficiar a los sectores más pobres de la población, estableciendo un sistema de compensación entre los salarios bajos y los altos, dentro de un criterio que mira a la satisfacción de las necesidades básicas del grupo familiar. Los medios para la consecución de este objetivo son básicamente el reconocimiento de un subsidio en dinero a los trabajadores cabeza de familia que devengan salarios bajos, subsidio que se paga en atención al número de hijos; y también en el reconocimiento de un subsidio en servicios, a través de programas de salud, educación, mercadeo y recreación.

La plurifuncionalidad que se le ha reconocido a las cajas de compensación, escenario del problema planteado sobre su regulación, nos coloca ante entidades, habilitadas al parecer para realizarlo todo, ${ }^{18}$ al extender su cobertura a sectores excluidos en general como parte del apalancamiento de la política estatal de redistribución. Esta situación debemos confrontarla con la creciente tendencia orientada por los organismos de control, en el sentido de que las Cajas

18 Artículo 16, decreto ley 789 del 2002 que adiciona el artículo 41 de la ley 21 de 1982 con otras funciones. deben ser autosuficientes en la generación de ingresos, la disminución progresiva de los recursos para cumplir con las funciones que inicialmente le fueron establecidas y la abundancia de controles a las que se encuentran sometidas

Los criterios de distribución de los recursos de las cajas, planteados en la ley 21 de 1982, han variado de la orientación inicial, y el subsidio no constituye por si sólo, mientras no entre al patrimonio del trabajador, un derecho adquirido sobre el aporte que hace el empleador sino un interés legítimo sobre los recursos que administran las cajas de compensación ${ }^{19}$, y finaliza la Corte Constitucional determinando que los Parafiscales, son rentas atípicas, en contradicción a sentencias constitucionales anteriores ya acotadas. Se anota que para la jurisprudencia constitucional el concepto de grupo socio-económico supera la noción de sector, y no solo cobija a quienes directa o exclusivamente han pagado la contribución, sino que puede extenderse a quienes en razón de los vínculos jurídicos, económicos o sociales que los ligan para con el respectivo grupo, pueden válidamente hacer uso y aprovechar los bienes y servicios suministrados por las entidades responsables de la administración y ejecución de tales contribuciones.

Estas razones aumentan los interrogantes alrededor del cumplimiento del retorno a favor del sector que lo genera ${ }^{20}$, ya que el sistema de cajas de compensación se ha orientado hoy a ser un soporte del Estado, orientado a cumplir con las políticas y programas de desarrollo social dirigidas a disminuir la vulnerabilidad y a mejorar la calidad de vida de los Colombianos ${ }^{21}$, reafirmada

19 Ver Corte Constitucional, Sentencia C-1173 del 8 de noviembre del 2001M.Clara Inés Vargas Hernández.

20 “ (...)Todos estos recursos son parafiscales, esto es, una afectación especial que no puede ser destinada a otras finalidades distintas a las previstas en la ley."Como ya lo tiene establecido esta Corporación, "la parafiscalidad hace relación a unos recursos extraídos en forma obligatoria de un sector económico para ser reinvertidos en el propio sector, con exclusión del resto de la sociedad..."Corte Constitucional. Sentencia No. C-449 de 1992.M.P.Alejandro Martínez Caballero.

21 Gaceta del Congreso,23 de agosto del 2002,proyecto de ley No.57 del 2002 por la cual se dictan normas para promover la empleabilidad y desarrollar la protección social. Exposición de motivos, Nuestra protección, ante las dramáticas cifras de desempleo que nos afectan, se extiende aún con más generosidad frente a los cabeza de hogar, los artistas, deportistas y escritores, el reasignarse cerca de 90 mil millones de pesos del sistema de Cajas de Compensación Familiar para que éstas personas en situación de desempleo puedan en forma temporal mantenerse afiliados al sistema de salud, lo que tendrá un impacto positivo en garantizar la salud de $50 \mathrm{mil}$ cabezas de hogar incluyendo a su grupo familiar, para llegar a más de 165 (sic) personas. En el mismo sentido, aliviando las cargas de los trabajadores independientes, quienes representan un muy alto porcentaje de nuestra población laboral, frente a aquellos que no tienen un grupo familiar. Para ellos y otra serie de grupos especiales, estamos partiendo con una modesta contribución su afiliación voluntaria a las cajas de compensación familiar, en un proceso de democratización de la recreación y el turismo social. 
en la exposición de motivos al proyecto de ley 789 del 2002.

Lo anterior, es el resultado de la tendencia del último tercio de siglo y el inicio del actual, por la cual las sociedades han reinterpretado sus visiones y sus actuaciones -programas e institucionalidad- en torno a sus sistemas de protección social. Tal es el ejemplo de Chile, país en el cual los programas de beneficios y prestaciones del sistema de seguridad social han sido orientados en virtud de los principios tradicionales de universalidad, integralidad, uniformidad, suficiencia y solidaridad. Sin embargo, la llamada modernización del sistema en Chile, ha venido a complementarlos a través de nuevas concepciones tales como administración privada, libertad de elección, subsidiaridad del Estado, descentralización y financiamiento ${ }^{22}$. Estas redefiniciones se han dado tanto por el predominio de los mecanismos de mercado, como forma privilegiada de asignar recursos privados y públicos, así como por la redefinición de las responsabilidades y las funciones del Estado, ${ }^{23}$ que debe concebir la política social en forma más integrada en la que se conjuguen los principios de universalidad, solidaridad y eficiencia, en forma acorde a las exigencias del desarrollo económico, superando la visión del Estado como protagonista, al crearse un nuevo escenario de aversión a lo público $\mathrm{y}$, como contrapartida, el enaltecimiento de lo privado.

Pero cómo hablar de empleabilidad, sin mejorar las condiciones del trabajador en calidad de vida. Para este propósito, el Gobierno propone extender los subsidios de las cajas de compensación familiar en materia de vivienda, que expiran próximamente, hasta el año 2006. Serán más de 200 mil millones de pesos que irrigarán para que cerca de 120 mil familias puedan tener techo en este cuatrienio.

No queremos cabezas de hogar sin empleo, siendo necesario comenzar a enfrentar este difícil camino por la vía de generar trabajo a través del microcrédito, que además de contar con todos los instrumentos de aquellas entidades que dentro y fuera del Gobierno concentran su esfuerzo para este propósito, se verá fortalecido con cerca de $30 \mathrm{mil}$ millones de pesos anuales. Recursos que se originarán en una supervisión menos costosa y más eficiente para las Cajas de Compensación y en un proceso gradual y plenamente justificado, de reducción de los gastos administrativos de estas entidades a quienes se les introduce un régimen de transparencia.

22 La ley que público en materia de Cajas de Compensación en Chile, fue la 18.833 que estableció un nuevo estatuto general que, entre otros aspectos, liberalizó al mercado de estas entidades, amplio la existencia de beneficios y servicios, simplificó los procesos adhesión de las empresas, acentuando la competencia y flexibilizó los requisitos para conformar y elegir Directorio, con lo que se reforzó el carácter autónomo y privado de estas instituciones.

23 CEPAL (2000), capítulo III Pág. 72. El reconocimiento universal de los derechos económicos ,sociales y culturales, ha cambiado el escenario de la política económica y social .Los bienes y servicios sociales tienen una connotación diferente de otros; son también derechos y bienes de valor social y se expresa en variados horizontes temporales, general y se ven afectados por externalidades especiales, y no son susceptibles de circular económicamente de manera independiente de las personas (excepción de transferencias en dineros y activos físicos como la vivienda).En esa medida y en tanto resultan esenciales para la vida de las personas o de la sociedad, su exposición a mecanismos de mercado requiere de grados elevados de regulación publica.
Esta estrategia de privatización está pensada para producir un conjunto de efectos benéficos que permitieran salir del estancamiento de un modelo que se encontraba desgastado y que fueron enunciadas en el consenso de Washington, a saber (Low Murtra y Gómez Ricardo, 1996, P.121).

- $\quad$ Aumento de la eficiencia: lo cual implica un estímulo a la competencia, a la presencia del sector privado (inclusive la inversión extranjera) y al crecimiento de la economía al igual que la disminución de los costos. Un darwinismo en la economía que permitiría la prevalencia del más fuerte mediante la decisión más óptima y un beneficio al consumidor (ventaja comparativa).

- Adopción de nuevas tecnologías: el sector privado resulta más inclinado a tales cambios.

- Ahondar los aspectos redistributivos: Democratizar la propiedad y, por dicha vía, reducir los niveles de pobreza.

- Atacar la corrupción así como el deficiente funcionamiento de ciertas empresas estatales.

- Sanear las finanzas públicas: generar ingresos para el Estado y, con ello, reducir los niveles de endeudamiento público y, en general, el déficit fiscal. Esto implica, igualmente, reducir las cargas asumidas por el Estado.

- A nivel político, legitimar el Estado mediante la tecnificación de sus decisiones, entre otros aspectos.

- Incrementar la participación ciudadana.

Por tanto, lo que se propende es evitar, que estas corporaciones se nutran de esquemas futuros de asistencia por parte del Estado e incluso suprimir los llamados parafiscales de obligatorio pago por parte de empleadores con trabajadores a su cargo. Esto, a nuestro parecer afecta a la clase trabajadora que cada vez debe pagar servicios con tarifas casi iguales a la del mercado, lo que incide en el criterio de retorno en beneficio del trabajador de menor ingreso, aunque $\mathrm{La}$ Corte Constitucional manifieste lo contrario ${ }^{24}$ al decir: ....No es una característica de la parafiscalidad la de que los sujetos pasivos de la contribución sean exactamente y de manera individual quienes reciban los beneficios derivados de la reinversión de los recursos captados. La correspondencia que exige la parafiscalidad se establece entre sectores, no entre personas, de lo cual resulta que lo esencial no es que el contribuyente individualmente considerado reciba una retribución directa y proporcional al monto de su contribución, sino que el sector que contribuye sea simultáneamente aquél que se favorece con la destinación posterior de lo recaudado. La contribución parafiscal que establece el precepto demandado no

24 Ver Corte Constitucional, Sentencia c-183 de 1997.M. P. José Gregorio Hernández. 
se queda en el reducido ámbito de los trabajadores que cotizan a las cajas de compensación familiar sino que se proyecta hacia los beneficiarios del régimen subsidiado de salud, incluidos trabajadores independientes y no cotizantes en dichas entidades, pero ello no vicia de inconstitucionalidad el precepto. Por el contrario, se realiza por esa vía el principio general de solidaridad.

El alcance concebido en el actual orden constitucional ${ }^{25}$, ha adoptado un concepto amplio de la seguridad social, que se plasma en el principio de cobertura universal, fundado en la dignidad de la persona humana y no en la mera relación laboral, y se caracteriza por buscar ofrecer a las personas el mayor número de servicios, auxilios, asistencias y prestaciones en general, apartándose de la escuela que la limita a lo básico.

En palabras de la Corte Constitucional, dicho orden también se ha encargado de precisar el compromiso que tienen los particulares en la realización de la seguridad social, pues al margen de atribuirle al Estado la función de dirección, coordinación, reglamentación y vigilancia, a éstos les asigna "el derecho y el deber concomitante de participar en la ampliación de la cobertura y en la ejecución de las prestaciones que les son propias ${ }^{\prime 26}$.

Dentro del esquema de funcionamiento de las Cajas de Compensación, la ley 789, estableció funciones que se agregan a las establecidas inicialmente por la ley 21 de 1982. Además en cuanto a temas como vulnerabilidad, ahorro y la implementación en la práctica de sus objetivos sociales, la ley permite su participación en asociaciones mutualistas de ahorro y préstamo, instituciones financieras de naturaleza cooperativa, cooperativas financieras $o$ cooperativas de ahorro y crédito, así como la creación del Fondo para la Atención Integral de la Niñez y Jornada Escolar Complementaria.

El reconocimiento del carácter de función pública de las actividades asociadas a la prestación del servicio que ejecutan las Cajas, conforme lo ha precisado la Corte Constitucional ${ }^{27}$ y soportado en el articulo 48 de la Carta Política, parte de considerar que con su labor se satisface una actividad de interés general, continua y necesaria, que ostenta el carácter de servicio público.

Sin embargo, las Cajas no sólo desarrollan función pública, ya que su misión institucional es plural y ha evolucionado

25 Ver Constitución Política. Artículos 48 y 49.

26 Ver Corte Constitucional, Sentencia C-408 de 1994.M. P. Fabio Morón Díaz.

27 Ver Corte Constitucional, Sentencia c-149 del 23 de marzo del 94, M. P. Eduardo Cifuentes Muñoz. con el tiempo, por lo que no a toda actividad y función de las Cajas se les puede clasificar como públicas, (Cortes, 2004, p.101),como por ejemplo la contratación por ocupación de sus centros vacacionales, los convenios con hoteles, o cualquier otro servicio de carácter privado y aún dentro de las de naturaleza pública, como el otorgamiento de subsidio monetario, de vivienda de interés social, al desempleado, o la liquidación de aportes, se deberá distinguir aquellas que tienen el carácter de administrativas y que entrañan el ejercicio de autoridad por parte de las cajas, en cumplimiento de un cometido público, colocando al administrado en condiciones de inferioridad. Estas precisiones son necesarias, en la medida que determinará en su operación la aplicación de determinadas normas e instituciones que la acercan al sector público, con efectos en materia de control y responsabilidades.

\section{El control y vigilancia sobre las cajas de compensación}

Por el carácter de agentes de la seguridad social, las Cajas de Compensación Familiar no pueden ser ajenas a la inspección, vigilancia y control del estado en cumplimiento del control administrativo interno o función de policía administrativa que ejerce el Presidente de la República a través de las Superintendencias ${ }^{28}$.

Esta entidad creada para este propósito, en el caso del Sistema de Cajas de Compensación, es la Superintendencia de Subsidio Familiar, ${ }^{29}$ y la Superintendencia de Salud ${ }^{30}$ en lo que tiene que ver con las funciones propias de esa actividad ${ }^{31}$,

28 Ver la Constitución Política artículo 189 y 48.

29 Los artículos 3o. de la Ley 25 de 1981 y 54 numeral 2o. de la Ley 21 de 1982, le confieren facultad a la Superintendencia del Subsidio Familiar para ejercer la inspección y vigilancia de las entidades encargadas de recaudar los aportes y pagar el subsidio familiar, con el propósito de que su constitución, funcionamiento y la realización de sus obras y programas sociales se ajusten a las leyes, decretos y estatutos internos.

30 Ley 789 del 2002, artículo 20 Régimen de Inspección y vigilancia. Corresponde a la Superintendencia de Subsidio Familiar frente a los recursos que administran las Cajas de Compensación Familiar y a la Superintendencia Nacional de Salud frente a los recursos que administren las entidades promotoras de salud, la inspección, vigilancia y control.

31 Ley 100 de 1993, ARTíCULO 217. De la Participación de las Cajas de Compensación Familiar. Las Cajas de Compensación Familiar destinarán el $5 \%$ de los recaudos del subsidio familiar que administran, para financiar el régimen de subsidios en Salud, salvo aquellas Cajas que obtengan un cuociente superior al 100\% del recaudo del subsidio familiar del respectivo año, las cuales tendrán que destinar un $10 \%$. La aplicación de este cuociente, para todos sus efectos, se hará de acuerdo con lo establecido en el artículo 67 de la Ley 49 de 1990, y a partir del 15 de febrero de cada año. Las Cajas de Compensación Familiar podrán administrar directamente, de acuerdo con la reglamentación que se expida para el efecto, los recursos del régimen subsidiado de que trata el presente artículo. La Caja que administre directamente estos recursos constituirá una cuenta independiente del resto de sus rentas y bienes. Las Cajas de Compensación Fami- 
cuando ejecutan directamente programas como entidades Promotoras de Salud o las relacionadas con la operación del régimen subsidiado en salud, ${ }^{32}$ tal como lo señala el decreto 1259 de junio 20 del 94 en su articulo cuatro.

Con la ley 789 del 2002 y la posibilidad de desarrollar la actividad financiera ${ }^{33}$, extendiendo la acción de las Cajas a varios sectores económicos, entra al panorama de control de las Cajas, la Superintendencia Financiera ${ }^{34}$, en los programas de microcrédito bajo cualquiera de las modalidades descritas en el articulo 7, parágrafo 3, numeral 11 y 20 del articulo 16 en forma directa, así como de forma indirecta en sus numerales 1,3 y 13 de la ley 789 del $2002^{35}$, al señalar que su inspección, vigilancia y control estará a cargo de la superintendencia de subsidios con sujeción a la reglamentación que expida la Superintendencia Bancaria, hoy Superintendencia Financiera, para establecimientos de crédito (registro, contabilización y establecimiento de provisiones de cartera entre otras), sin

liar que no cumplan los requisitos definidos en la reglamentación, deberán girar los recursos del subsidio a la subcuenta de solidaridad del Fondo de Solidaridad y Garantía".

32 "Por el cual se reestructura la Superintendencia Nacional de Salud" Artículo 4o. sujetos de inspección, vigilancia y control. 6. Las Cajas de Compensación Familiar, en cuanto estén autorizadas para la prestación de servicios de salud y exclusivamente respecto de esta actividad, conforme las disposiciones sobre la materia, respetando su régimen legal, sistema financiero y autonomía administrativa.

33 Ley 789 del 2002, Artículo 16 numeral 3: Participar, asociarse e invertir en el sistema financiero a través de bancos, cooperativas financieras, compañías de financiamiento comercial y organizaciones no gubernamentales cuya actividad principal de la respectiva institución sea la operación de microcrédito, conforme las normas del Estatuto Orgánico del Sector Financiero y demás normas especiales conforme la clase de entidad.

34 Ley 789 del 2002, Artículo 20 Parágrafo 3‥ La inspección, vigilancia y control de las operaciones de crédito previstas en el numeral 11 del artículo 16 de esta ley será ejercida por la Superintendencia de Subsidio Familiar dando aplicación a las reglamentaciones que dicte, de manera general para los establecimientos de crédito, la superintendencia Bancaria para la administración del riesgo crediticio, especialmente en los temas relacionados con el registro, contabilización y establecimiento de provisiones sobre cartera de créditos.

35 Las Cajas podrán operar los programas de microcrédito a través de las siguientes alternativas;

De manera directa e individual, a través de unidades de crédito y cartera

Por medio de asociaciones de Cajas

Obligatoriamente por conducto de una entidad crediticia de la cual haga parte la Caja como accionista y sea vigilada por la Superintendencia Financiera

En participación, asociación o con inversión en bancos, cooperativas financieras, compañías de financiamiento comercial y ong `s, cuya actividad principal sea la operación de microcrédito de conformidad con la reglamentación que al respecto expida el Gobierno A través de la constitución o inversión en fondos de capital de riesgo o cualquier otro instrumento financiero aplicable a la actividad, con asociación entre Cajas o con terceros al efecto y con la posible participación como accionistas de los trabajadores afiliados, previa determinación del Gobierno en tales eventos

A través de convenios o alianzas estratégicas con otras entidades las cuales deben estar autorizadas por la Superintendencia financiera. perjuicio de la inspección, vigilancia y control que ejerza la superintendencia financiera en razón del sujeto sobre las entidades en las cuales participe, se asocie o invierta la caja en el desarrollo de programas de micro crédito. Se presenta en este caso y en razón de la cláusula general de competencia, inspección, vigilancia y control de la Superintendencia financiera sobre las cajas, (para efecto de organización y funcionamiento responsabilidad de los administradores, manejo de portafolios, provisiones) la coexistencia de los controles de ambas Superintendencias, requeriría formulas de coordinación interinstitucional y economía que la ley no establece.

En cuanto a la actividad financiera atribuida a las cajas con la ley 920 de diciembre del 2004 que adicionó el articulo 16 de la ley 789 del 2002, con sus empresas, trabajadores pensionados y desempleados "afiliados", en los términos y condiciones que reglamente el Gobierno Nacional, le asigna a la Superintendencia Financiera la función de inspección, vigilancia y control sobre las operaciones y organización de las secciones especializadas de ahorro y crédito que lleguen a constituir las Cajas de Compensación, lo que crea un régimen adicional y superpuesto de autoridad y control ante el ordinario ejercido por la Superintendencia de Subsidio, sin que a la fecha se haya reglamentado hasta donde llegan las funciones de una y otra que impidan la duplicidad y garanticen la eficiencia y economía en el mismo.

Otros aspectos relacionados con el control y la supervisión de actividades que impliquen competencia o de protección al consumidor ${ }^{36}$ que, sean consecuencia, o se deriven de las funciones que desarrollen las cajas, y que se puedan presentar entre estas corporaciones o entre estas y sus usuarios, estarían a cargo de la Superintendencia de Industria y Comercio, conforme a lo establecido en el parágrafo 5 ,articulo 21 de la ley 789 comentada, En este último caso, el interrogante que surge es, ¿Cuál es la competencia que está adscrita a la Superintendencia de Industria y Comercio?, ¿La que se da entre las cajas? ¿La que se presente entre estas y sus agentes económicos de empresas frente a los servicios prestados por ellas? ¿A que consumidor protege? ¿Es al afiliado de las Cajas que accede a sus servicios? ¿O tal vez sea el no afiliado que utiliza los servicios de mercadeo, recreación o capacitación?

La Ley 789 de 2002, ratificó estas competencias y desarrolló, abundantemente, aspectos relacionados con la transparencia

36 Ley 789 del 2002, artículo 21, Parágrafo $5^{\circ}$. Las Cajas de Compensación Familiar estarán sometidas a la inspección, vigilancia y control de la Superintendencia de Industria y Comercio en materia de competencia y protección al consumidor. La vigilancia se adelantará conforme lo previsto en las Leyes 155 de 1959 y 256 de 1996 y el Decreto-ley 2153 de 1992 y demás normas que los reglamenten o modifiquen. 
en el actuar de las Cajas de Compensación Familiar, a tal punto que, dentro de las atribuciones que se le reconocen a la Superintendencia de Subsidios, está la relacionada con la descripción e investigación por aquellas de prácticas no autorizadas o inseguras en que incurran las Cajas y que, "imponen un análisis sobre el principio de legalidad y tipicidad así como de juez natural, pues concentran en una autoridad que no tiene rango popular legislativo la facultad de establecer conductas prohibidas a particulares y de investigarlas y sancionarlas" (Cortes, 2004, p.128),

Pareciera que conforme a la redacción de ley, los conflictos de competencia que se presenten entre Cajas en razón de la afiliación de las empresas, y que hacen parte de la esencia del sistema, debiera ser conocido por la Superintendencia de Industria y Comercio refiriéndose a una competencia generalizada, sin embargo un vistazo a las competencias expresas adscritas a la Superintendencia de Subsidios en el artículo 21, se orienta a regular el proceso de ofrecimiento, comercialización, prestación de servicios y manejo de la competencia entre las Cajas y en especial los parágrafos 1 y $3,{ }^{37}$ en cuanto se refiere a la selección adversa, procesos de comercialización enfocados a la afiliación y violación de la ley en el caso de traslados o retenciones de empleadores afiliados. Además, dentro de las funciones adscritas al Superintendente de Subsidio Familiar en el artículo 7 del decreto 2150 está la de vigilar e intervenir el proceso de afiliación de los empleadores y el acceso de los servicios. En lo que se refiere a protección al consumidor, la misma ley 789 del 2002 en su artículo 24, asignó facultades a la Superintendencia de Subsidios en lo atinente a la vigilancia de la información que se le suministre a los usuarios ${ }^{38}$

37 ( )Parágrafo $1^{\circ}$. La Superintendencia de Subsidio Familiar sancionará las prácticas de selección adversa, así como los procesos de comercialización que no se enfoquen a afiliar a los diferentes niveles empresariales por parte de las diferentes Cajas. El Gobierno Nacional a través del Ministerio del Trabajo y Seguridad Social podrá definir mecanismos de afiliación a través de los cuales se pueda escoger Caja de Compensación por parte de empresas que no han sido objeto del proceso de promoción, estando la respectiva Caja obligada a formalizar su afiliación Los trabajadores con una mayoría superior al $70 \%$, podrán estipular períodos hasta de cuatro (4) años frente a la permanencia en una Caja de Compensación, período que se reducirá sólo cuando se demuestre falla en los servicios acreditada plenamente por la entidad de supervisión ...

Parágrafo $3^{\circ}$. Cuando se compruebe el traslado o retención de empleadores mediante violación de alguna de las normas vigentes; además de la sanción personal al representante legal, que será proporcional al monto de los aportes, la Superintendencia ordenará que la afiliación regrese a la Caja de afiliación anterior con devolución de los aportes menos los subsidios pagados.

38 ( )12. Velar porque las entidades vigiladas suministren a los usuarios la información necesaria para lograr la mayor transparencia en las operaciones que realicen, de suerte que les permita, a través de elementos de juicio claros y objetivos, escoger las mejores opciones del mercado 21. Expedir el reglamento a que deben sujetarse las entidades vigiladas en relación con sus programas publicitarios con el propósito de ajustarlos a las normas vigentes, a la realidad jurídica y en relación al reglamento que debe expedir la Caja por programas publicitarios que persigue, como uno de sus objetivos, prevenir propaganda comercial que favorezca la competencia desleal.

Sin embargo, en concepto $05091321^{39}$ emanado de la Superintendencia de Industria y Comercio, ésta ratificó su competencia residual en asuntos de competencia desleal y prácticas restrictivas de la competencia que se presentaren en "el sector las Cajas de Compensación". Por tanto y mientras exista norma especial y expresa que faculte a la Superintendencia de Subsidios para la inspección, entonces ésta será la que aplique el control. En caso contrario, y por mandato del mismo artículo 21 parágrafo 5 de la ley mencionada, el control estará a cargo de la Superintendencia de Industria y Comercio, máxime la de aquellos conflictos de competencia que surjan entre las Cajas y las entidades que no pertenezcan al Sistema (como por ejemplo, agencias de viaje, empresas comercializadoras, de servicios de recreación etc.).

Es de anotar que la competencia general está a cargo de la Superintendencia de Subsidios como la máxima autoridad,

y económica del servicio promovido y para prevenir la propaganda comercial que tienda a establecer competencia desleal.

39 Concepto 05091312 de noviembre 3 del 2005 (...) En cuanto a las facultades administrativas en competencia desleal, al contrario de lo que sucede con las facultades jurisdiccionales en dicho tema, la competencia de esta Entidad es residual, es decir, entraremos a conocer del asunto solamente si no existe otra Entidad que tenga facultad expresa para ello, por cuanto, como ya se expuso, en esta materia contamos con las mismas facultades que en promoción de la competencia y prácticas comerciales restrictivas, tema en el cual esta Superintendencia tiene competencia residual.

Por lo tanto, por no existir norma que faculte a otra autoridad para conocer de las infracciones al régimen de competencia desleal en el sector de las cajas de compensación familiar, concluimos que la competencia a este respecto se encuentra radicada en la Superintendencia de Industria y Comercio.

En cuanto a prácticas restrictivas de la competencia, señalamos, nuevamente, que esta Entidad tiene competencia residual. Así, de acuerdo con lo señalado en el Decreto 2153 de 1992, corresponde a la Superintendencia de Industria y Comercio velar por la observancia de las normas sobre promoción de la competencia y prácticas comerciales restrictivas, a menos que exista una norma que faculte a otra autoridad para ello. Para tal fin, cuenta con la facultad de adelantar investigaciones e imponer las sanciones que corresponda por el incumplimiento de dichas normas.

Las atribuciones de esta Entidad se predican, entonces, respecto de las conductas constitutivas de prácticas comerciales restrictivas que se desarrollen en todos los sectores, salvo en los casos en que esta facultad haya sido conferida a otra autoridad. Por ello, se ha sostenido que la Superintendencia de Industria y Comercio cuenta con una cláusula general de competencia en esta materia.

En conclusión, teniendo en cuenta que no existe norma de carácter legal que le otorgue la competencia a otra autoridad pública para velar por la observancia de las normas sobre prácticas comerciales restrictivas en lo que respecta a las Cajas de Compensación Familiar, concluimos que ésta se encuentra radicada en la Superintendencia de Industria y Comercio.(...). 
situación que se mantiene a la fecha en que continúa operando de forma autónoma, con un control posterior a las Cajas ${ }^{40}$ y que, al decir de Cortes (2004, p.339-340) "complica la interpretación de la norma en el ejercicio del control posterior por parte de la superintendencia de subsidios en los casos de autorizaciones previas en relación con operaciones o actuaciones de las Cajas", según lo preceptuado en la ley, en aplicación de los modernos principios de auditoria que para nada afecta la inspección y vigilancia a su cargo, la cual podrá ejercer en todo momento a través de los mecanismos ordinarios de inspección tales como la solicitud de información, la recepción de quejas y la realización de visitas a estas corporaciones.

Del mismo modo, se precisa en la ley 789 que, tratándose de actividades que demanden autorización de otras autoridades públicas, es responsabilidad de la respectiva caja o entidad la consecución de los permisos, licencias o autorizaciones, limitándose la autoridad de control a verificar el cumplimiento de los porcentajes de ley ${ }^{41}$.

Es importante acotar que cuando las Cajas se asocien, inviertan o participen en la creación de terceras personas jurídicas para el cumplimiento de las funciones a su cargo, se someterá al control indirecto de la Superintendencia de Economía Solidaria cuando su participación sea en empresas del sector solidario, tales como cooperativas de ahorro y crédito o multiactivas con sección de ahorro y crédito. Así mismo, cuando las funciones se desarrollen en el ámbito del turismo, estarán sometidas al control del Ministerio de Comercio, Industria y Turismo, conforme a lo establecido por la ley 300 de 1996 o en tratándose de vivienda y sus subsidios estarán bajo la tutela del Ministerio de Ambiente, Vivienda y Desarrollo Social conforme a la ley 49 del 90 y ley 3aㅡ del 91.

No es posible dejar de lado, el control fiscal que sobre tales corporaciones tendría la Contraloría General de la

40 Ley 789 del 2002, artículo 20, parágrafo 1 ( ) El Control se ejercerá por regla general de manera posterior, salvo en aquellas Cajas en que la Superintendencia de Subsidio Familiar mediante resolución motivada que así lo disponga salvo en aquellas cajas en que la Superintendencia de Subsidio Familiar mediante resolución motivada que así lo disponga.

41 Ley 789 del 2002. Artículo 20. Régimen de Inspección y Vigilancia. Las autorizaciones que corresponda expedir a la autoridad de inspección, vigilancia y control, se definirán sobre los principios de celeridad, transparencia y oportunidad. Cuando se trate de actividades o programas que demanden de autorizaciones de autoridades públicas, se entenderá como responsabilidad de la respectiva Caja o entidad a través de la cual se realiza la operación, la consecución de los permisos, licencias o autorizaciones, siendo función de la autoridad de control, verificar el cumplimiento de los porcentajes de ley. Las autorizaciones a las Cajas se regularán conforme los regímenes de autorización general o particular que se expidan al efecto. El Control, se ejercerá de manera posterior sin perjuicio de las funciones de inspección y vigilancia.
República e incluso las Contralorías territoriales sobre los recursos por el hecho de ser parafiscales. De acuerdo con lo expresado en concepto No.003583 $3^{42}$ en el cual se hacen unas consideraciones jurídicas acerca de la naturaleza de la parafiscalidad, y con referencia a la Resolución 5289 de $2001^{43}$ emanada de la Contraloría General de la República, cuando los recursos derivados de la parafiscalidad, se apliquen a funciones públicas que puedan cumplir las Cajas, tal es el caso de la prestación del servicio público de Salud que $y$, conforme lo ha manifestado la Corte Constitucional en la sentencia c-828 del 2001, se convierte en la prestación de un Servicio público en reemplazo del Estado. ${ }^{44}$

42 Es claro que el control que ejerce las Superintendencias es netamente administrativo y concurrente con otra clase de controles, como el fiscal, por tanto el control y vigilancia que ejercen estos organismos no excluye aquel que por mandato legal deben realizar las contralorías.

Bajo este entendido, la competencia de la Contraloría General de la República para fiscalizar las Cajas de Compensación Familiar está circunscrita al orden nacional. Luego para efecto de ejercer tal facultad es preciso determinar si estas empresas ejercen la actividad de afiliación de empleadores en todo el país, i si por el contrario la ejercen en el ámbito departamental o Municipal. De manera que no existe duda de la naturaleza de parafiscales de los dineros que administran las Cajas de Compensación familiar, y en este entendido también es claro que debe existir control fiscal a los mismos.

43 por la cual se reglamenta la rendición de cuenta, su revisión y se unifica la información que se presenta al máximo organismo d Control Fiscal y que comprende exclusivamente a las Cajas de Compensación Familiar del orden Nacional.

44 Sentencia Constitucional c-828 de octubre 8 del 2002.M P. Eduardo Montealegre Linett 'Hay que admitir que al delegarse la prestación del servicio público de salud a una entidad particular, ésta ocupa el lugar del Estado para algo muy importante cual es la prestación de un servicio público; pero eso no excluye que la entidad aspire a obtener una legítima ganancia. Así está diseñado el sistema. Pero, lo principal es que se tenga conciencia de que lo que se recauda no pertenece a las EPS, ni mucho menos entra al presupuesto nacional ni a los presupuestos de las entidades territoriales, sino que pertenece al sistema general de seguridad social en salud, es, pues, una contribución parafiscal. Por tal razón, la Corte no puede ser indiferente al equilibrio estructural del Sistema Nacional de Seguridad Social en Salud, al plan obligatorio de salud del régimen subsidiario y a los principios de universalidad y solidaridad que deben ir paralelos. La vigilancia de estos preceptos forma parte de uno de los objetivos del Estado social de derecho: la solución de las necesidades insatisfechas de salud' las entidades administradoras actúan como simples intermediarias entre los recursos que manejan y los usuarios del servicio, asimilándose su función a un contrato de aseguramiento especial en el que las EPS asumen el riesgo de la actividad y la administración de los recursos. Pero no se trata de un contrato de seguro clásico. No "porque en primer lugar, construye un manejo financiero de prestación media para todos por igual, tanto para el régimen contributivo, como para el régimen subsidiado, $\mathrm{y}$ en segundo lugar, los recursos, una vez son captados por el Sistema de Salud, no le pertenecen a quien los cancela, sino al sistema en general. Las cotizaciones que hacen los afiliados al sistema de salud no se manejan como cuentas individuales en donde existe una relación conmutativa entre lo que se paga y lo que se recibe. Estos aspectos, de la relación entre afiliados y asegurador distinguen de fondo el contrato de aseguramiento en salud del contrato de seguros tradicional. 
El acelerado proceso legislativo que se dio con la emisión de la ley 789 del 2002, ha dado lugar, tal como se ha descrito, a disposiciones contrarias entre sí y su aplicación suscita dificultades operativas y de interpretación, abandonándose el sano criterio de especialidad funcional en la inspección, vigilancia y control de las Cajas de compensación, que había establecido hasta ese momento la ley, en razón del carácter subjetivo del controlado, a cargo de la Superintendencia de Subsidios.

\section{Conclusiones}

La Jurisprudencia emanada de la Corte Constitucional, presenta en sus pronunciamientos, conceptos ambivalentes, frente al carácter del subsidio familiar, equiparándolo a recursos de naturaleza parafiscales, que aportados obligatoriamente por los empleadores en las cajas de compensación familiar, son contribuciones obligatorias que se reinvierten en el mismo sector, "con exclusión del resto de la sociedad". Sin embargo, en otros pronunciamientos, al ser proyectado hacia otros sectores, se modifica, y en cumplimiento del "principio de solidaridad", se denominan parafiscales especiales llamados "atípicos".

Por tanto, se requiere un análisis pormenorizado del sistema que permita determinar su integralidad con una real articulación de sus recursos, su ubicación en el panorama de la seguridad social y en otros sectores económicos y sociales, sin olvidar las proyecciones y realidades que tienen estas corporaciones incluyendo, la revisión de las condiciones dentro de las cuales ejercen su labor las cajas de compensación familiar y, particularmente, la competencia que entre ellas se desata en zonas del territorio Colombiano.

La Superintendencia, debe contar con una serie de atribuciones de carácter preventivo, cautelar y correctivo a través de las cuales se salvaguarden los recursos del sistema de subsidio familiar, criterio que también ha desarrollado el Consejo de Estado cuando tuvo la oportunidad de conceptuar sobre el particular ${ }^{45}$.

Se debe establecer un régimen de inspección claro en cuanto a su interpretación y aplicación.
Las instituciones de control y vigilancia, deben garantizar su buen funcionamiento, de forma "autónoma e independiente", sin olvidar no obstante la necesidad de establecer instancias de participación de todos los actores para conocer sus opiniones y propugnar por un mejor servicio ${ }^{46}$.

Los sistemas de información juegan un papel fundamental, para lo cual se requiere estructurar eficaces mecanismos de información, capacitación e información a la ciudadanía en materia del derecho a la seguridad social.

Se debe garantizar la financiación oportuna y adecuada de la función reguladora por parte de la Superintendencia de Subsidios que determine la conformación de personal idóneo e independiente en el ejercicio de sus funciones de inspección vigilancia y control.

Es necesario, la aplicación de instrumentos para el mantenimiento de mercados competitivos entre cajas de compensación por su intervención en mercados ampliados con servicios diversificados.

En eventos de conflicto de competencia real o aparente, para el ejercicio de la inspección, vigilancia y control, deberán tenerse en cuenta los principios constitucionales de la actuación administrativa y los postulados de coordinación interinstitucional y economía de tal manera que aunque otra superintendencia, Ministerio u organismo del Estado deba ejercer acciones permanentes de inspección, sobre las Cajas, esta deberá adelantarse en forma coordinada con la Superintendencia del caso, sea la de Subsidio o de cualquier otra, competente por el principio de especialidad y así evitar duplicidad en la información.

Estas conclusiones no pretenden ser la panacea ante la problemática estudiada, sino una reflexión frente a la necesidad de determinar con claridad las tareas a cargo de un órgano de inspección y vigilancia único, con definición de reglas precisas que permitan cumplir con el objeto de garantizar a los usuarios del servicio un actuar responsable por parte de las Cajas de Compensación, frente a la multiplicidad de funciones adscritas por la ley que tocan diferentes sectores económicos y sociales y su importancia en al ámbito de la seguridad social.
45 Ver Consejo de Estado, Sala de Consulta y Servicio Civil, concepto de 10 de diciembre de 1997, radicación 1055, Consejero Ponente Luís Camilo Osorio Isaza.
46 CEPAL 2002, Capítulo III, equidad desarrollo y ciudadanía, página 81. 


\section{Referencias}

Ayala, U (2001). Hacia una red de protección social para Colombia. Informe presentado al Banco Mundial y al Banco Interamericano de Desarrollo. Bogotá. Fedesarrollo.

Caballero, Herrera, N. (2005) Cajas de compensación precursoras de la responsabilidad, Memorias, XVII congreso nacional sobre responsabilidad social empresarial. Bogotá.

CEPAL (2002), Capítulo III, equidad, desarrollo y ciudadanía. Agenda económica. México.

Cortes González, J.C. (2004) Sistema del subsidio familiar en Colombia: Hacia la protección social. Bogotá. Biblioteca CIESS.

Cortes González, J.C. (2006) Política y seguridad social; un reto permanente para la democracia en Revista latinoamericana de derecho social. México, Universidad Autónoma de México.

Cobo A.J., (2005) Responsabilidad Social del Sistema de Cajas de Compensación Familiar. Memorias XVII congreso nacional sobre responsabilidad social empresarial. Bogotá. Fedesarrollo.

Low Mutra E. y Gómez J. (1996) Teoría Fiscal. Bogotá. Editorial Externado de Colombia.

Ministerio de La Protección Social, Superintendencia del Subsidio Familiar (1998), el subsidio familiar en Colombia, compilación normativa. Jurisprudencia y Doctrina, Bogotá.

Ministerio de la Protección Social, superintendencia del subsidio familiar, (2004) Antología Normativa del Subsidio Familiar, Bogotá D.C.

Ruiz Gómez F, (2003) Centro de proyectos para el desarrollo, documento de trabajo, Retos de mercado para las cajas de compensación familiar en Colombia. Bogotá, Universidad Javeriana.

\section{Legislación}

Congreso de la República de Colombia, (1959). Decreto-Ley 155

Congreso de la República de Colombia, (1968). Decreto-Ley 717

Congreso de la República de Colombia, (1981). Ley 25

Congreso de la República de Colombia, (1982). Ley 21

Congreso de la República de Colombia, (1988). Decreto 341

Congreso de la República de Colombia, (1989). Ley 71

Congreso de la República de Colombia, (1989). Decreto 784

Congreso de la República de Colombia, (1990). Ley 49

Congreso de la República de Colombia, (1991). Ley $3^{\text {a }}$

Congreso de la República de Colombia, (1992). Decreto-ley 2153

Congreso de la República de Colombia, (1992). Decreto 2150

Congreso de la República de Colombia, (1993). Ley 100

Congreso de la República de Colombia, (1994). Ley 115

Congreso de la República de Colombia, (1994). Decreto 1259

Congreso de la República de Colombia, (1996). Ley 300

Congreso de la República de Colombia, (1996). Decreto-Ley 256

Congreso de la República de Colombia, (2000). Ley 633

Congreso de la República de Colombia, (2002). Ley 789

Congreso de la República de Colombia, (2003). Ley 828

Congreso de la República de Colombia, (2004). Ley 920 
Consejo de Estado de la República de Colombia, (1997) Concepto Sala de Consulta y Servicio Civil, radicación 1055, C P. Luis Camilo Osorio Isaza.

Consejo de Estado de la República de Colombia, (2006). Concepto Sala de Consulta y Servicio Civil, C P. Flavio Augusto Rodríguez Arce.

Contraloría General de la República de Colombia, (2001). Resolución 5289.

Contraloría General de la República de Colombia, (2002). Concepto No.003583.

República de Colombia, Constitución Política, (1991).

Gaceta del Congreso, (2002). Proyecto de ley No.57 "por la cual se dictan normas para promover la empleabilidad y desarrollar la protección social" exposición de motivos.

Giraldo C. (2005), sistema integral de protección social, Memorias del XVII congreso nacional sobre responsabilidad social empresarial Bogotá.

Superintendencia de Industria y Comercio, (2005) Concepto 05091312.

Superintendencia del Subsidio Familiar, (2004) Resolución 374.

Superintendencia del Subsidio Familiar, (1997) Circular 011.

Superintendencia del Subsidio Familiar, (1988) Circular 007.

\section{Sentencias}

República de Colombia, Corte Suprema de Justicia, (1987). Sentencia 32 de 19 de marzo de 1987.

República de Colombia, Corte Constitucional. (1992). Sentencia No. C-449 de 9 de julio de 1992.M. P. Alejandro Martínez Caballero.

República de Colombia Corte Constitucional, (1992) Sentencia No. C- 575 de 1992, MP Alejandro Martínez Caballero. República de Colombia Corte Constitucional, (1994) Sentencia No. C -149 de 1994, MP. Eduardo Cifuentes.

República de Colombia Corte Constitucional, (1994) Sentencia C-408 de 1994.M. P. Fabio Morón Díaz.

República de Colombia Corte Constitucional, (1997) Sentencia No. C -183 de 1997, M.P. José Gregorio Hernández.

República de Colombia Corte Constitucional, (1997) Sentencia No. C -508 de 1997, M.P. Vladimiro Naranjo Meza.

República de Colombia Corte Constitucional, (2001) Sentencia No. C -1173 de 2001, M.P: Clara Inés Vargas.

República de Colombia Corte Constitucional, (2003) Sentencia No. C 655-2003, MP Rodrigo escobar Gil.

República de Colombia Corte Constitucional, (2003) Sentencia No. T-712 de 2003, MP .Jaime Córdoba Triviño.

República de Colombia Corte Constitucional, (2004) Sentencia No. C -586 de 2004.

República de Colombia Corte Constitucional, (2006) Sentencia No. C -041-2006, MP Clara Inés Vargas.

República de Colombia Corte Constitucional, (2007) Sentencia No. C -393-2007, MP: Manuel José Cepeda Espinosa. 